\title{
Transplacental Passage of Islet Cell Antibody in Infants of Diabetic Mothers
}

\author{
A. J. TINGLE, G. LIM, V. J. WRIGHT, J. E. DIMMICK, AND J. A. HUNT \\ Department of Pediatrics and Pathology, University of British Columbia, Vancouver, Canada and Department of \\ Medicine, Lion's Gate Hospital, North Vancouver, Canada
}

\begin{abstract}
Summary
The incidence of pancreatic islet cell antibody (ICAb) was assessed in the cord blood and sera of infants of diabetic mothers (IDM). ICAb activity was detected in the cord blood of 10 of 36 $(27.8 \%)$ consecutive IDM studied and in 0 of $111(0 \%)$ cord bloods of normal control infants. In all instances, ICAb activity in the cord sera was of the immunoglobulin (IgG) class and was associated with ICAb in maternal sera at the time of delivery. No correlation was observed between the incidence of ICAb in IDM and alterations in fetal growth parameters, congenital malformation rates, cord blood insulin levels, or the incidence of neonatal complications. The evidence would support transplacental passage of ICAb from diabetic mothers to their offspring, but would not support a primary pathogenetic role for ICAb in the clinical or metabolic alterations observed in these infants.
\end{abstract}

\section{Speculation}

The detection of ICAb in the cord blood of IDM at birth would suggest a possible role for transplacentally-acquired ICAb in the pathogenesis of the clinical, metabolic, and morphologic abnormalities observed in these infants.

A characteristic spectrum of clinical, metabolic, and morphologic abnormalities have been reported in infants born to diabetic mothers $(2,3,5,11)$. While various hypotheses have been advanced to explain the pathogenesis of these abnormalities, considerable controversy remains (11). The demonstration of antibody directed against pancreatic islet cells in the circulation of diabetic populations $(1,6,7)$ and the recent case report of ICAb in the cord blood of an IDM (4) have suggested a possible role for transplacentally-acquired ICAb in the pathogenesis of some of the clinical and morphologic abnormalities observed in these infants. The present study was undertaken to assess the incidence of ICAb in cord blood and sera of IDM and to determine if the presence of ICAb is associated with any specific alterations in clinical or metabolic function.

\section{MATERIALS AND METHODS}

\section{SUBJECTS}

Of 36 consecutive diabetic pregnancies studied, 9 were classified according to White (12) as class A, 10 as class B, 11 as class $C$, and 6 as class $D$. The age of the diabetic mothers at the time of delivery ranged from 18-35 yr (mean 27.0). The gestational age of the infants ranged from 33-40 wk (mean 37.3) and the birth weights ranged from $2480-5280 \mathrm{~g}$ (mean 3505 ). Serum samples were obtained from the mother by venipuncture within $24 \mathrm{hr}$ of delivery. Cord blood was obtained from the IDM and followup serum samples were obtained 7 days and 6 months postpartum. Control cord blood samples were obtained from 111 consecutive normal infants. All serum specimens were stored at $20^{\circ} \mathrm{C}$. for no longer than 3 months before use.

\section{PROCEDURES}

Antibody activity directed against pancreatic islet cells was detected using the indirect immunofluorescent technique (7). Fresh human pancreas obtained from cadaveric renal transplant donors of blood group $O$ was employed as the tissue substrate and $5 \mu \mathrm{m}$ cryostat sections were air dried and fixed in acetone at room temperature for $10 \mathrm{~min}$. Undiluted human sera were applied for $30 \mathrm{~min}$, followed by fluorescein-conjugated goat antihuman IgG, IgA, or IgM (Kent Laboratory). Sera positive for ICAb demonstrated a characteristic pattern of cytoplasmic immunofluorescence in all pancreatic islet cells. Titers were measured in serial doubling dilutions of serum beginning at a 1:2 dilution. Preliminary studies ruled out the presence of islet immunofluorescence related to antiinsulin activity by absorbing the sera overnight at $4^{\circ} \mathrm{C}$ with porcine insulin (Schwarz/Mann) $400 \mu \mathrm{g} / \mathrm{ml}$ and repeating the immunofluorescent studies. Insulin levels in cord sera were determined using a double antibody radioimmunoassay technique (Amersham). All statistical calculations were performed using a step-wise discriminant analysis to separate between the ICAb positive and ICAb negative populations jointly on the basis of the following variables: maternal age at the time of delivery; duration of maternal insulin therapy; duration of maternal diabetes, number of maternal pregnancies, and cord blood insulin levels.

\section{RESULTS}

The overall incidence of ICAb activity in the cord blood of 36 consecutive IDM studied was $27.8 \%$. No ICAb activity was observed in 111 normal control infants studied over the same time period. In all instances, ICAb activity was of the IgG class and was associated with positive ICAb determinations in maternal sera at the time of delivery. Titers of ICAb activity in positive maternal sera ranged from 1:1-1:16 and were consistently within a single doubling dilution of the corresponding cord sera. In two diabetic mothers in which serial ICAb determinations were made throughout the course of the pregnancy, positive ICAb levels were detected from the 12th wh of gestation through full term. ICAb levels remained positive in 7 of 7 IDM tested at 7 days postpartum and were consistently negative by 5-6 months.

Step-wise discriminant analysis of the data indicated no correlation $(P>0.05)$ between the presence or absence of ICAb and any single variable or linear combination of variables including maternal age at time of delivery, the number of maternal pregnancies (Fig. 1), the duration of maternal diabetes (Fig. 2), the duration of maternal insulin therapy (Fig. 3), or cord blood insulin levels (Fig. 4).

No apparent association was noted between the incidence of ICAb in cord blood and congenital malformations (congenital heart disease, renal vein thrombosis etc.); neonatal complications (hypoglycemia, hypocalcemia, hyperbilirubinemia, respiratory distress syndrome); fetal gestation age; fetal growth parameters (Fig. 5); or maternal class of diabetes (Fig. 6) although the number in the study group are small. 


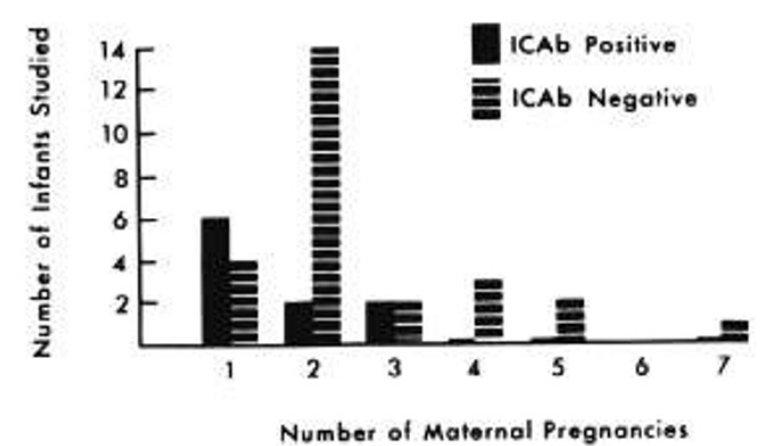

Fig. 1. Incidence of ICAb in the cord blood of IDM in relation to the number of maternal pregnancies.

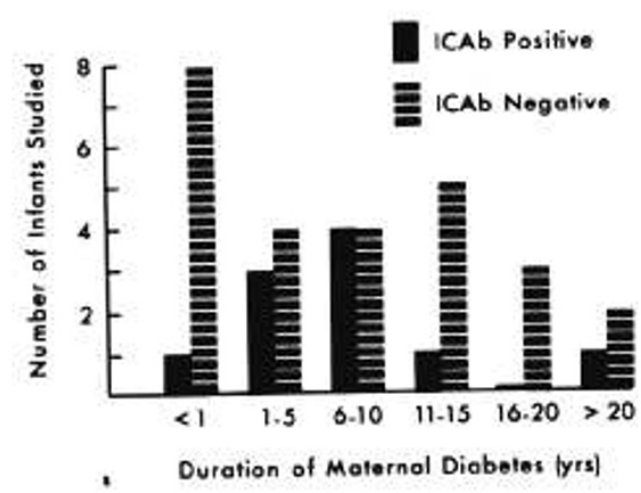

Fig. 2. Incidence of ICAb in the cord blood of IDM in relation to the duration of diabetes before delivery.

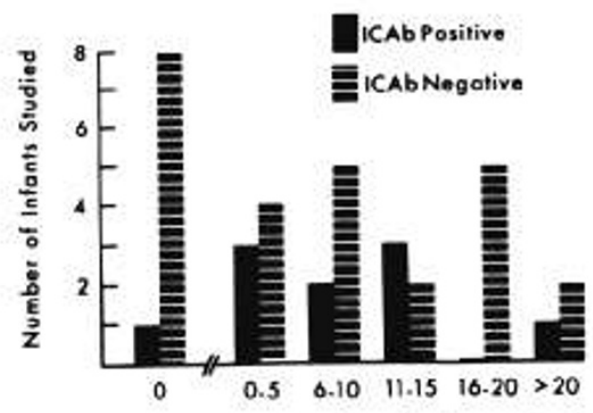

Duration of Maternal insulin Therapy (yrs)

Fig. 3. Incidence of ICAb in the cord blood of IDM in relation to the duration of maternal insulin therapy before delivery.

\section{DISCUSSION}

The present study confirms the presence of ICAb activity in a significant proportion of IDM at birth and for a limited time thereafter. The ICAb would appear to be transplacentally acquired from the maternal circulation based on the observation of ICAb activity only in those infants whose mothers had ICAb detected at the time of delivery; on the restriction of ICAb activity to the IgG class; and on the limited duration of antibody persistence in the postnatal period.

Transplacental passage of maternal autoantibody into the fetal circulation has been reported previously in a wide variety of disease states $(4,8,9)$. The effect on fetal development and neonatal clinical course has been variable. The transfer of platelet antibodies in idiopathic thrombocytopenic purpura, antibodies to conducting tissue in systemic lupus erythematosus, thyroid-stimulating immunoglobulins in thyrotoxicosis, and antibodies directed against acetylcholine receptor protein in myasthenia gravis $(8-10)$ have been associated with a transient disorder in the infant similar to that of the mother. However, the transplacental passage

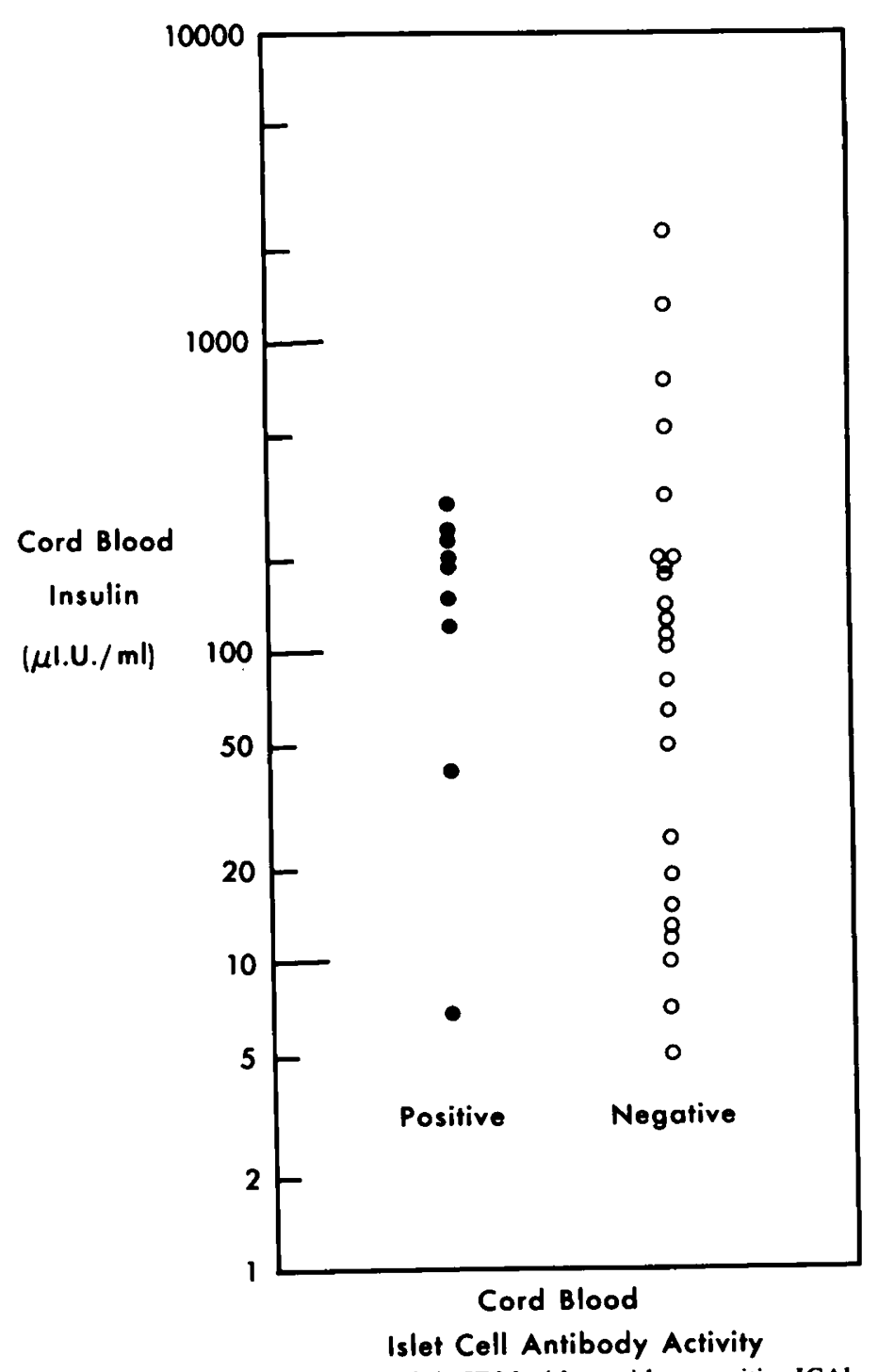

Fig. 4. Cord blood insulin levels in IDM with or without positive ICAb titers.

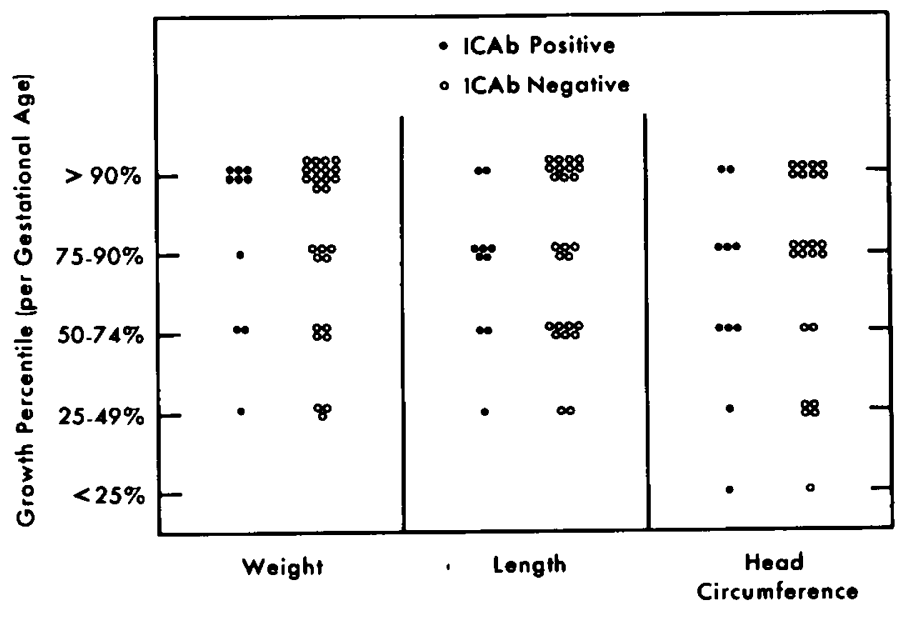

Fetal Growth Parameter

Fig. 5. Fetal growth parameters in IDM in relation to the incidence of ICAb in cord blood.

of gastric parietal cell and intrinsic factor antibodies in pernicious anemia $(9,10)$ have had no reported effect on the newborn infant. In the present study, transplacental passage of ICAb into the fetal circulation is reported to have no apparent effect on fetal growth 


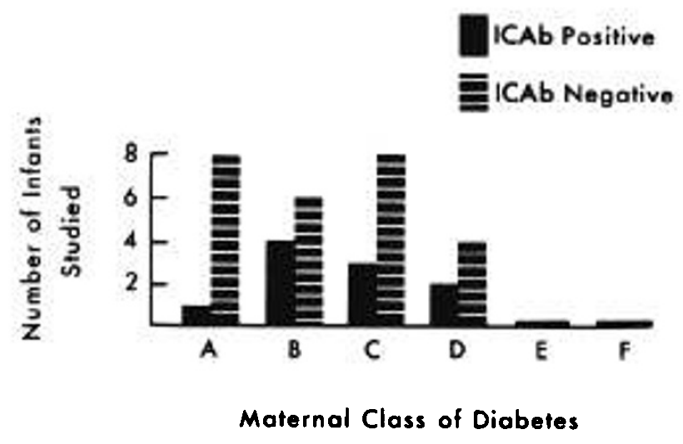

Fig. 6. Incidence of ICAb in the cord blood of IDM in relation to the maternal class of diabetes.

and development, the incidence of congenital malformations, cord blood insulin levels, or the neonatal clinical course. However, a possible role still remains for ICAb in the production of morphologic alterations in pancreatic islets observed in a proportion of infants of diabetic mothers. In particular, the reports of periinsular inflammatory cell infiltrates and islet fibrosis in $\operatorname{IDM}(5,11)$ would be consistent with this hypothesis.

\section{REFERENCES AND NOTES}

1. Bottazzo, G. G., Florin-Christensen, A., and Doniach D.: Islet-cell antibodies in diabetes mellitus with autoimmune polyendocrine deficiencies. Lancet, 2: 1279 (1974).

Copyright $(C) 1979$ International Pediatric Research Foundation, Inc. $0031-3998 / 79 / 1312-1323 \$ 02.00 / 0$
2. Cornblath, M., and Schwartz, R.: Infant of the diabetic mother. In: M. Cornblath and R. Schwartz: Disorders of Carbohydrate Metabolism in Infancy. pp. I15I54 (W. B. Saunders, Philadelphia, 1976).

3. Farquhar, J. W.: The child of the diabetic woman. Arch. Dis. Child., 34: 76 (1959).

4. Gamlen, T. R., Aynsley-Green A., Irvine, W. J., and McCallum, C. J.: Immunological studies in the neonate of a mother with Addison's disease and diabetes mellitus. Clin. Exp. Immunol., 28: 192 (1977).

5. Hultquist, G. T., and Olding. L. B.: Pancreatic-islet fibrosis in young infants of diabetic mothers. Lancet, 2: 1015 (1975).

6. Irvine, W. J., McCallum. C. J., Gray, R. S., Campbell, C. J., Duncan, L. J. P., Farquhar, J. W., Vaughan, H., and Morris, P. J.: Pancreatic islet-cell antibodies in diabetes mellitus correlated with the duration and type of diabetes, coexistent autoimmune disease, and HLA type. Diabetes. 26: 138 (1977).

7. MacCuish, A. C., Irvine, W. J., Barnes, E. W.. and Duncan, L. J. P.: Antibodies to pancreatic islet cells in insulin-dependent diabetics with coexistent autoimmune disease. Lancet, 2: 1529 (1974)

8. Namba, T., Brown, S. B., and Grob, D.: Neonatal myasthenia gravis: report of two cases and review of the literature. Pediatrics, 45: 488 (1970).

9. Scott, J. S.: Immunological diseases in pregnancy. Prog. Allergy, 23: 321 (1977).

10. Scott, J. S.: Pregnancy: nature's experimental system. Lancet, I: 78 (1976).

11. Wellman, K. F., and Volk, B. W.: The islets of infants of diabetic mothers. In: B. W. Volk and K. F. Weliman: The Diabetic Pancreas. pp. 365-380 (Plenum Press, New York, 1977).

12. White, P.: Symposium on diabetes mellitus: pregnancy complicating diabetes. Am. J. Med., 7: 609 (1949).

13. The authors thank Theresa Yang and Dorothy Mallory for excellent technical assistance. The authors wish to thank Dr. Michael Schulzer for carrying out the statistical analysis.

14. This research was supported by the Medical Research Council of Canada.

15. Requests for reprints should be addressed to: A. J. Tingle, M. D., Division of Immunology, Children's Hospital, 250 West 59th Avenue, Vancouver, B. C. Canada, V5X $1 \times 2$.

16. Received for publication August 28, 1978

17. Accepted for publication January 8, 1979 